\title{
Second Language Attrition and Activation: Are Multiple Intelligence Profiles and Semantic Categorization Playing a Role?
}

\author{
AMIR ROUHSHAD \\ University of Imam Sadiq, Tehran, Iran
}

Received: 18 July 2009 / Accepted: 7 January 2010

ISSN: 1697-7467

\begin{abstract}
This study aimed to investigate the spread of activation and part-set effect in attrited semantic sets, the relationship between multiple intelligences and second language attrition, and the differences between high and low attriters' intelligence levels in 54 lower-intermediate and beginner participants after 1 to 35 years of disuse. After identifying attrited words through a 133-word checklist of 12 semantic sets, translation and match-making tasks were devised to investigate the spread of activation. The results showed that the spread of activation is not significantly different between the recognition and production levels or across proficiency levels, and that it is unrelated to the length of disuse. Furthermore, this study shows that the part-set effect exists in semantic sets, so it could be hypothesized that the quick relearning of languages might be due to the spread of activation. Additionally, a significant relationship was found between musical intelligence and the amount of attrition in low attriters, as well as a significant difference between high and low attriters in terms of intrapersonal intelligence. Thus, these might be a few of the variables that are key in reducing the amount of attrition in this study.
\end{abstract}

Keywords: attrition; spreading activation; multiple intelligences.

Activación y atrición en una segunda lengua: ¿Desempeñan algún rol los perfiles de inteligencia múltiple y la categorización semántica?

RESUMEN: Este estudio se propone investigar la extensión de la activación y el efecto de los grupos semánticos, la relación entre las inteligencias múltiples y la atrición con la L2, así como las diferencias entre los niveles de inteligencia de los sujetos que sufren una alta y baja atrición en una muestra de 54 participantes de nivel bajointermedio y principiantes después de un periodo sin usar la L2 que se extendió de 1 a 35 años. Después de identificar las palabras que sufrieron atrición por medio de una lista de 12 grupos semánticos, se diseñaron tareas de traducción y de relación de elementos para investigar el alcance de la activación. Los resultados muestran que la extensión de la activación no es significativamente diferente entre el reconocimiento y los niveles de producción o a través de los niveles de competencia, y que no está relacionada con el periodo de falta de uso de la L2. Además, el estudio muestra que el efecto de la atrición existe en los grupos semánticos, por tanto se podría establecer la hipótesis de que el re-aprendizaje rápido de las lenguas puede relacionarse con el ámbito de la atrición. Por otra parte, se encontró una relación significativa entre la inteligencia musical y la cantidad de atrición en los sujetos de baja pérdida de compe- 
tencia y una diferencia significativa entre los sujetos con alta y baja atrición en términos de inteligencia intrapersonal. De este modo se identifican algunas de las variables clave en la disminución de la atrición.

Palabras clave: atrición, extensión de la activación, inteligencias múltiples

\section{INTRODUCTION}

One of the concerns of language teachers is how to improve vocabulary teaching to ensure better learning on the part of learners and to make the learning process enjoyable for them. Finkbeiner and Nicol (2003), for example, remark that a long-standing assumption in SLA has been that presenting vocabulary in semantically related sets is an effective method because in doing so, learners are provided with greater precision and this helps them to delineate boundaries better. They also maintain that this assumption has encouraged several textbook authors to organize their books based on this view. This idea has also found support in Neely (1991), who shows, in a semantic priming experiment, that the semantic relationship between prime and effect facilitates recognition. To explain such a result, Finkbeiner and Nicol (2003) remark that this facilitation of recognition can be accounted for by the pre-activation of semantic features of the target due to the activation of the shared semantic features of the prime. However, Damian, Vigliocco, and Levelt (2001) claim that in production-word- and picture-naming - this pre-activation in the context of same-category items is counterproductive; this, in authors' idea, is because when a concept is activated, it leads to the co-activation of lexical entries that are semantically related. Then, co-activated lexical items compete with one another in being retrieved, which hinders output. Moreover, to further criticize the idea of presenting words in semantic sets, Finkbeiner and Nicol (2003) remark that presenting learners with semantic sets is not effective because the number of learning trials necessary to reach a predetermined learning criterion for semantically related words is more than that for semantically dissimilar items, as suggested in several studies (Higa, 1963; Kintsch \& Kintsch, 1969; Wation, 2000; Tinkham, 1993, 1997, as cited in Finkbeiner \& Nicol, 2003).

To delve into the nature of the spread of activation, this study intends to investigate the question for attrited semantic sets at production and recognition levels in attriters. We use attriters with different proficiency levels and length of disuse because this can have implications for teaching vocabulary and may provide an explanation for the speedy recovery of attrited languages mentioned in Hansen, Umeda, and Mckinney (2002).

Additionally, the possibility that learners might undergo attrition after they lose their contact with a language is worrisome; as Tomiyama (1999) maintains, first and second language attrition set in within six months of disuse. It should be noted that according to Oxford (1982), there are many and various variables, including cognitive ability, which might influence the amount of attrition - and according to Johnson and Johnson (1999), this ability consists of intelligence and aptitude. Following Gardner's (1993, as cited in Mahdavy, 2008) Theory of Multiple Intelligences (MI), Po-ying (n.d.), Shearer (2006) and Williams (2006) have shown that linguistic intelligence is not the only form of intelligence that is involved in language learning. Hence, identifying the possible intelligences that might influence the amount of attrition seems to be useful. Therefore, this study intends to investigate the relationship between Multiple Intelligences and the amount of attrition, as well as the differences between the high and low 
attriters in terms of their MI profiles. It should be noted that MI can just be part of the overall picture and that there may be many other variables at work as well, as remarked by Oxford (1982).

\section{Defenitions of ATtrition}

Kopke (2004) remarks that there are many and various definitions of language attrition in literature and that each considers the phenomenon from a different perspective: linguistic, sociolinguistic or psycholinguistic. These perspectives deal with what is attrited, the cause of attrition, and how the attrition takes place, respectively. For an example of a linguistic perspective on the definition of attrition, we can refer to Vago (1991), who defines attrition as a structural deviation from the standard-however, from a sociolinguistic perspective, Jaspert and Kroon (1989:80) define it as «a form of language change that makes potential communication problems between individuals and the community of which they consider themselves a member». From a psycholinguistic perspective, there is also Oxford (1982), who defines attrition as loss of proficiency, and Sharwood Smith (1983, as cited in Kopke, 2004) who defines it as a reduction in accessibility. In this study, as I am dealing with the spread of activation to words that are inaccessible to attriters, I have taken a psycholinguistic approach to attrition-more specifically that of Sharwood Smith.

\section{Cause of attrition}

Kopke (2004) has pointed out that there are two possible cognitive processes that may lead to attrition. One of them is the decay theory, which claims that lack of use gradually leads to the extinction of memory traces. According to Hansen (2001), this is in contrast to what many psychologists believe; in their view, something that is committed to memory will not be expunged. Further, Marefat and Rouhshad (2007) have demonstrated that even continuing students who were in touch with L2 English, underwent attrition; thus, attrition is not limited just to the people who lose their contact with the language. Next is the influence theory, which holds that language information is modified under the influence of other languages; this indicates that new information influences previous information. This theory is in line with interference theory put forth by Weltens and Grendel (1993).

\section{RETENTION OF WORDS}

de Groot and Keijzer (2000) have suggested that concrete words are learned easily and forgotten late compared to abstract words. They put forth two theories explaining why concrete words are better retained: the context availability theory and dual coding theory. The former holds that «concrete words may have more contexts associated with them because there is more information in their memory representation and this additional information may help anchor the new foreign language words» (de Groot \& Keijzer, 2000:18). 
Dual coding theory holds that

A concrete word would be represented in both the image system and the verbal system of the language to which it belonged, but an abstract word would be represented only in the verbal system of its language. Hence, the concrete word is more solidly embedded in the memory and would be less likely to be forgotten than the abstract word. (de Groot \& Keijzer, 2000:19)

\section{LEARNING VS. RELEARNING}

Hansen et al. (2002) state that the speed of relearning a language for the second time is dramatically faster than the speed of learning it for the first time, especially for children. This claim has been supported by many studies (Berman, 1979; Slobin, Dasigner, Kyntay \& Toupin 1993; Wode, 1996 as cited in Hansen et al., 2002; and Yukawa (2001)). Hansen (2001) points out that when activation drops even lower than the levels required for retrieval at production and recognition levels, then that item cannot be retrieved. She also remarks that through relearning, the activation level will be raised to a level that makes it retrievable, but the items that are to be learned for the first time cannot reach the required activation level as quickly as forgotten words reach it through relearning. She goes on to say that in relearning, production requires a higher level of activation than recognition because of the difficulty involved in memory retrieval in language production that is caused by competition between co-activated lemmas. This idea is also supported in de Bot, Martens, and Stoessel (2004).

\section{Second language Residual KNowledge}

Hansen (2001) maintains that psychologists are of the opinion that something committed to memory will not be expunged and that even for an attrited language there are residues of knowledge that can be reactivated. Accordingly, de Bot and Stoessel (2000) gave L2 attriters a matching task in which they had to match L2 Dutch words with L1 German words. Although attriters had acquired L2 Dutch during their early childhood, around 30 years prior to the study, they could answer $50 \%$ of the matching items correctly. Thus, it was suggested that attriters retained a considerable part of their Dutch vocabulary even after 30 years of disuse.

\section{Part-Set relearning}

Atkins (2001) maintains that part-set relearning means that relearning previously known words affects the activation and the hence recovery of other forgotten words. Atkins also points out that this could be due to the associative nature of human memory or the notion of spreading activation. However, the experiment reported in his study did not support a part-set effect for words. 


\section{Multiple intelligences (Mi) theory}

Gardner (1993, as cited in Mahdavy, 2008) refers to previous IQ tests as inappropriate because they were restricted to just logic and language and did not take into consideration other intelligences. Therefore, he identified 7 intelligences; he added another one later, but emphasized that we all have different combinations of intelligences and that they can improve throughout life.

According to Shearer (1996), the multiple intelligences are as follows:

Musical: The ability to understand the pitch, rhythm, and tone of music and to recreate or reproduce music by means of instruments or voice.

Kinesthetic: The ability to express oneself through complicated movements of body. This includes timing and a sense of coordination of whole-body movements.

Logical-Mathematical: The ability to perceive cause-and-effect relationships between two phenomena, objects or actions.

Spatial: The ability to think in pictures and to understand the visual world accurately; the ability to think in 3 dimensions and transform understanding to visual experience through the imagination.

Linguistic: The ability to express oneself and understand complex meanings through the use of language. This form of intelligence involves sensitivity to the meaning of words, the order of words, sounds, rhythms, and inflections.

Interpersonal: The ability to think and understand others and be sympathetic to them. This involves understanding differences between people and interacting with them effectively.

Intrapersonal: The ability to recognize one's strengths and weaknesses and set a plan to reach personal goals. This includes the ability to monitor oneself in interpersonal relationships.

Naturalist: The ability to understand the natural world, such as plants, scientific studies and animals.

\section{Mi inspired Language teaching}

To the eyes of a novice teacher, all intelligences except the linguistic one seem irrelevant, whereas they can all be at the service of language teachers if they are exploited properly. To show how to manipulate different intelligences in the classroom context, Po-ying (n.d.) remarks that we can inspire the use of spatial, interpersonal, logical-mathematical and linguistic intelligences all in one task: asking students to look at two pictures related to the custom of hand-shaking and social distances in Eastern and Western customs and then discuss in groups the differences at hand or plan a debate on the subject and then perform it for the class. As far as word teaching is concerned, from my perspective, it seems that MI-inspired language teachers have a variety of methods that they can employ. For example, to inspire the use of musical intelligence, they can teach words by means of songs, especially at the elementary level; to involve kinesthetic intelligence, Total Physical Response can be utilized; to involve logical-mathematical intelligence, which includes inductive and deductive reasoning skills, students should be taught the roots and affixes of words; to inspire the use of spatial intelligence, the use of pictures is recommended; to involve linguistic intelligence, synonyms and antonyms can be presented while defining the meanings of words or words can be taught in context; and finally, to involve interpersonal 
intelligence, students can be put in different groups and asked to use the new words to perform a task cooperatively.

Shearer (2006) investigates the MI profiles of $2159^{\text {th }}$ grade high school students in the U.S at varying reading levels. Using the Ohio State Achievement Tests, participants were divided into three groups: high-, mid-, and low-level readers. This enabled them to see if there were distinctive MI profiles in these readers. The results revealed that in addition to linguistic intelligence, logical-mathematical, interpersonal, and intrapersonal intelligences were significantly different among the three groups. In particular, very good readers use a constellation of all four intelligences in reading a text. The author notes that logical-mathematical intelligence helps readers to think logically about the text and its meaning for other people and themselves. Moreover, he remarks, interpersonal intelligence is helpful because it gives readers the capacity to place themselves in the role of the author of a passage and consider the perspectives of the characters in a story, which in turn will increase semantic understanding and textual comprehension. It also helps them to understand the point of view, directions, and explanations provided by the teacher, which will also facilitate the development of reading skill in learners. Moreover, he remarks that self-management of anxiety and problem-solving skill as embodied in intrapersonal and logical-mathematical intelligences help readers to «stick with the process» when they encounter unknown words or complex sentences.

Mahdavy (2008) investigates the relationship between Gardner's eight intelligences and test scores on the Listening portion of the TOEFL and IELTS. The results reveal that all forms of intelligence positively contributed to participants' performance on the listening part of the IELTS and TOEFL but that only linguistic intelligence had a statistically significant relationship with them. Furthermore, the results of the stepwise regression analysis showed that linguistic intelligence is the only predictor of listening performance among the eight intelligences. Thus, the implications of this study, according to the author, are that for better listening comprehension, teachers should provide learners who have low levels of linguistic intelligence with further support and encourage them to take on more linguistic tasks.

Williams (2006) argues that certain structures in grammar, like coordinate structures, pluralizing nouns, relative clause types, and definite articles, can be taught through mathematical concepts by drawing on students' knowledge of elementary mathematical concepts.

\section{This STUdy}

Annually, a substantial portion of budgets is earmarked by Departments of Education for teaching English as a second or foreign language to learners. However, we have noticed that learners undergo attrition after a short period of disuse; for example, Tomiyama (1999) maintains that first and second language attrition set in within six months of disuse. Therefore, the question of how to present vocabulary to avoid hindrance and optimize learning during the learning period, and of what are the possible measures for immunization during the disuse period, can seem pressing for language teachers. As far as vocabulary presentation is concerned, according to Finkbeiner and Nicol (2003), some textbook authors and teachers present words in semantically related sets to make second language learners more interested in language learning, although Damian, et al. (2001) show that in production, such presentation is counterproductive because of the co-activation of lemmas and the competition among them. 
Hence, given the authors' argument against such presentation, I would suggest that teaching vocabulary in semantic sets can be more of a hindrance than a help. This study aims to investigate the spread of activation and the part-set effect in attrited semantic sets at production and recognition levels for participants with different proficiency levels and length of disuse, and to evaluate the relationship between the spread of activation and length of disuse. If this study shows that the spread of activation survives through several years of disuse, this will lend support to the notions of spreading activation and, hence, the part-set effect; account for the speedy relearning of an attrited language as mentioned in the referenced above; and have implications for the exponents of presenting words in semantic sets to reconsider their idea.

As far as possible immunization against disuse is concerned, the relationship between different MI profiles and L2 vocabulary attrition, as well as the differences between high and low attriters in terms of their MI profiles, are investigated in this study. It should be noted that according to Oxford (1982), there are many and various variables, including cognitive ability, which might influence the amount of attrition - and according to Johnson and Johnson (1999), this ability consists of intelligence and aptitude. Hence, identifying the possible influencing intelligences is just part of the total picture because these are not the only determining variables.

\subsection{Research questions}

This study aims to investigate the following questions:

1. Is the Part-set effect at work in production and recognition levels in attrited semantic sets after several years of disuse on the part of the participants?

2. Is there any significant difference between the spread of activation in attrited semantic sets at recognition and production levels in lower-intermediate and beginner participants?

3. Is there any significant relationship between the spread of activation (production \& recognition) and the length of disuse for the participants?

4. Is there any significant relationship between the MI profile scores and the amount of attrition in high and low attriters?

5. Is there any significant difference in MI profile scores between high and low attriters?

\subsection{Method}

\subsubsection{Participants}

The participants in this study were 54 university-educated and school-educated adult Iranians (male \& female) who underwent 1 to 35 years of language disuse. The schooleducated group, made up of beginners who had not studied at university, included 15 attriters; the length of their entire education ranged from 9 to 12 years. The university-educated group who were equivalent to lower-intermediate learners included 39 attriters, who received their B.S in different majors like Mathematics, Law, Engineering, etc.

The beginner participants had attended English classes three hours per week for a maximum of 6 years during their education, and the lower-intermediate participants, apart from their previously mentioned classes in school, took 3 credits in general English and 3 credits in English for Specific Purposes (ESP) at university. The medium of instruction in all the English 
classes that the participants had taken was Persian, and they were taught using the Grammar Translation Method. Their ages ranged from 25 to 55. It was assured that none of the participants had contact with the English language during the disuse period or that at least contact was minimal.

\subsubsection{Instruments}

Because part of this study intends to investigate the spread of activation among lemmas that by nature share most of their semantic features, a 133-concrete word list of 12 semantic sets from the English course-books that participants had studied during their education was developed. Furthermore, cognateness was tightly controlled, and just one word was considered to be a cognate. Additionally, match-making tasks that varied for each participant were developed to investigate the possible activation of words at the level of recognition. Moreover, translation tasks from English to Persian (L2 to L1) were used to investigate the possible activation of words at the level of production. Also, a panel of experts approved the content validities of the tasks.

To assess the MI profiles of the participants, the Multiple Intelligences Developmental Assessment Scales (MIDAS), developed by Shearer (1996), were used. Shearer (1996) maintains that research on the reliability and validity of MIDAS has revealed that the MIDAS scales can provide a reasonable estimate of one's MI. It is a 6-point Likert-type questionnaire based on MI Theory. Also, in this study, the Persian translation of the MI questionnaire that was also used by Mahdavy (2008) in Iran was used.

\subsubsection{Procedure}

In stage one, the words in the semantic sets were scrambled in a list. This list of words was presented to the participants individually, and they were asked to write the Persian translation of the words for each item in the blank provided within 30 minutes or otherwise check in the space provided whether they had known the word before and forgotten it at the time of the experiment. Moreover, at this stage, they were given translated MI questionnaires and asked to complete them within 35-45 minutes. Later, the questionnaires were sent to the instrument developer for assessment. Then, the researcher interviewed the participants to assess their proficiency levels and learn about the amount of their contact with the English language during the period of disuse.

After a one-week interval, during stage two, the words that the participants had not been able to translate and claimed that they had known before, as well as the words that had been translated wrongly, were extracted from the scrambled list and categorized into their relevant semantic sets. Therefore, the translation tasks at this stage were different for each participant. To check the spread of activation at the production level, for each semantic set the participants were given a translation task from English to Persian; this L2- to -L1 translation task was also used by de Bot et al. (2004). In each set, participants were given the Persian translation of just one word for activation and, based on it, were asked to try to recall and write the Persian translations for the other words.

After a one-week interval, during stage three, in order to check the spread of activation at the recognition level, the words that had been translated accurately in the previous stage 
were removed from each semantic set, and the researcher designed a match-making task for the rest of the words. In this stage as well, for each set, participants were given the Persian translation of just one of the words for activation; based on it, they were required to try to match the other words with the Persian meanings that were given.

The spread of activation at the production level was investigated prior to that at the recognition level because if it had been investigated in reverse order, the spread of activation at the production level could not have been investigated; most of the attrited words would have been activated at the recognition level, and very few words would have been left for the production stage. This is because, according to de Bot et al. (2004) and Hansen (2001), recognition requires a lower level of activation than production.

\section{Results}

\subsection{Results of Question 1}

First of all, in order to answer the first question, which tests the part-set effect, the total number of words that were activated at each level following the initial activation by the researcher was counted. Table 1 below shows the total number of attrited words and the number of words that were activated by attriters at each level.

Table 1. Total number of attrited and activated words at each level.

\begin{tabular}{lcc}
\hline & Attrited words & Activated words \\
\hline Production & 780 & 349 \\
Recognition & 230 & 126 \\
\hline
\end{tabular}

As the table clearly shows, following the initial activation by the researcher, $44 \%$ of the attrited words were activated at production level and $54 \%$ at recognition level even after several years of disuse.

\subsection{Results of Question 2}

Table 2 shows the descriptive statistics for beginner and lower-intermediate participants' performance in terms of the spread of activation at the production and recognition levels.

Table2. Descriptive statistics for beginner and lower-intermediate participants' performance on spread of activation at production and recognition levels.

\begin{tabular}{cccc}
\hline Level & & \multicolumn{2}{c}{ Spread of activation } \\
\hline \multirow{3}{*}{ Beginner } & Mean & Production & Recognition \\
& SD & .51 & .57 \\
& $\mathrm{~N}$ & .21 & .36 \\
& & 14 & 7 \\
Lower-intermediate & Mean & .45 & .61 \\
& SD & .19 & .28 \\
& $\mathrm{~N}$ & 36 & 24 \\
\hline
\end{tabular}


Participants in this study numbered 39 at the lower-intermediate level and 15 at the beginner level. However, as the table above shows, production level data are available for only 14 beginner and 36 lower intermediate participants. This is because in stage one of the data collection, the number of checked words by some participants was so few and varied that the words could not be categorized into a semantic set. Moreover, after data collection for the production level, it was impossible to collect data for some of the participants for their recognition level because they had recalled most of the attrited words at the production level and very few and varied words had been left that could not be categorized into a semantic set. That is why the number of beginner and lower-intermediate participants decreased to 7 and 24, respectively, during stage three.

To see if there was any significant difference in the spread of activation between production and recognition levels for lower-intermediate participants, a Paired Samples Test was run. As the results show, there is no significant difference between the spread of activation at production and recognition levels $(\mathrm{t}(38)=.54, \mathrm{p}=.59>.05)$. As far as the beginner participants are concerned, the results of the Paired Sample Test show that there is no significant difference between the two levels $(\mathrm{t}(14)=1.55, \mathrm{p}=.14>.05)$.

According to Weltens and Grendle (1993), length of education is an index of proficiency level; therefore, in order to investigate the effect of proficiency level on the spread of activation at production and recognition levels, the performance levels of the two groups were compared. Accordingly, an Independent Sample Test was run to see if there was any significant difference between the two groups in their activation at the production level. As the result show, there is no significant difference between the two groups $(\mathrm{t}(48)=-.99, \mathrm{p}=.32>.05)$. This means that none of the groups significantly outperformed the other as far as the spread of activation at the level of production was concerned. Then, in order to address the same question at the recognition level, another Independent Sample Test was run. The results showed that even at the recognition level, there was no significant difference between the two groups $(\mathrm{t}(29)=.33$, $\mathrm{p}=.74>.05)$.

\subsection{Results of Question 3}

The third question concerns the relationship between the spread of activation and the length of disuse among all the participants. First, the relationship between the spread of activation at production level and the length of disuse was investigated. The results of the nonparametric Pearson Correlation Test showed that there is no significant relationship between the length of disuse and activation at the production level $(\mathrm{r}=.037, \mathrm{p}=.8>.05)$. This means that the spread of activation at this level is not weakened as the length of disuse is prolonged. To check the same correlation at the recognition level, another non-parametric Pearson Correlation Test was run. Similarly, at this level, no significant relationship was found $(r=.012, p=.95>$ .05 ). That is to say, the spread of activation at this level is not weakened as the length of disuse is prolonged.

\subsection{Results of Question 4}

To answer the fourth research question, first we needed to divide all of the participants who had forgotten 3 to 67 words into two groups: high-attriters and low-attriters. As there was 
no cut-off point in the literature for this purpose, after consultation with K. de Bot (personal communication, March 6, 2009) and P. Meara (personal communication, February 19, 2009) it was decided to consider the median for this purpose, with the understanding that the median is less affected by the standard deviation. Hence, participants who had forgotten more than 19 words were grouped as high attriters and those who had forgotten 19 words or less were grouped as low attriters. Thus, based on this index, we have 26 high attriters and 28 low attriters in this study.

As far as the MI profiles are concerned, each participant received a score of 0-100 for each of the intelligences. According to Shearer (1996), a score of 0-19 indicates very low intelligence, 20-39 indicates low intelligence, 40-59 indicates moderate intelligence, 60-79 indicates high intelligence, and 80-100 indicates very high intelligence. Further, the Alpha reliabilities of the profile scores based on MIDAS were as follows: musical: .87; kinesthetic: .73; logical-mathematical: .88; spatial: .84; linguistic: .82; interpersonal: .90; intrapersonal: .85; naturalist: .85 .

To answer this question, an attempt was made to see if there was any significant relationship between MI profile scores and the amount of attrition in both groups of attriters. The following table provides the correlations between MI profile scores and the amount of attrition for high and low attriters plus the $\mathrm{p}$ value for each correlation.

Table 3. Correlations between MI profile scores and the amount of attrition in high and low attriters and the related $p$ values.

\begin{tabular}{ccccc}
\hline & \multicolumn{2}{c}{ Highattriters } & \multicolumn{2}{c}{ Low attrite } \\
\hline Moltiple intelligences & Correlation & $\mathrm{p}$ & Conelation & $\mathrm{p}$ \\
Mhasical & .045 & 82 & $-386^{*}$ & .04 \\
Kiresthetic & -.134 & 51 & -.007 & .97 \\
Logical- Mathernatical & .196 & 33 & -.035 & .86 \\
Spatial & .069 & .73 & -.098 & .61 \\
Linguistic & .258 & 20 & -.175 & .37 \\
Irterpersoral & .134 & 51 & .056 & .77 \\
Intrapersoral & .243 & 23 & .010 & .96 \\
Natural & .346 & 08 & -.031 & .87 \\
\hline
\end{tabular}

*Significant at $\mathrm{p}=0.05$.

In high attriters, the results of Pearson Correlation Tests for all of the intelligences showed that none of the MI profile scores was significantly correlated with the amount of attrition. As with high attriters, no significant relationship was found for low attriters except for the musical intelligence score, which was significantly and negatively correlated with the amount of attrition $(\mathrm{r}=-.386, \mathrm{p}=.04<.05)$.

\subsection{Results of Question 5}

The last research question is concerned with the differences in MI profile scores between high and low attriters. Below is the table showing the descriptive statistic results, plus the $t$ and $\mathrm{p}$ values for each Independent Sample Test. 
Table 4. Descriptive statistics for high and low attriters' MI profile scores plus the $t$ and $p$ values for each independent sample test.

\begin{tabular}{|c|c|c|c|c|c|c|c|c|}
\hline Multiple inte lligences & & attriters & & & rattriter & & & \\
\hline $\begin{array}{l}\text { Musical } \\
\text { Kinesthetic } \\
\text { Logical- Mathematical } \\
\text { Spatial } \\
\text { Linguistic } \\
\text { Irterpersonal } \\
\text { Intrapersoral } \\
\text { Natural }\end{array}$ & $\begin{array}{l}\text { Mean } \\
28.04 \\
34.47 \\
43.92 \\
41.82 \\
45.78 \\
55.61 \\
50.20 \\
37.66 \\
\end{array}$ & $\begin{array}{l}\text { SD } \\
16.48 \\
15.22 \\
13.48 \\
14.23 \\
12.73 \\
17.30 \\
12.32 \\
17.45\end{array}$ & $\begin{array}{l}\mathrm{N} \\
26 \\
26 \\
26 \\
26 \\
26 \\
26 \\
26 \\
26 \\
26 \\
\end{array}$ & $\begin{array}{l}\text { Mean } \\
28.67 \\
39.27 \\
50.08 \\
49.57 \\
47.18 \\
55.73 \\
57.14 \\
33.08 \\
\end{array}$ & $\begin{array}{l}\text { SD } \\
19.06 \\
16.95 \\
18.18 \\
20.01 \\
14.61 \\
17.54 \\
14.28 \\
15.24 \\
\end{array}$ & $\begin{array}{l}\mathrm{N} \\
28 \\
28 \\
28 \\
28 \\
28 \\
28 \\
28 \\
28 \\
\end{array}$ & $\begin{array}{r}t(52) \\
-0.13 \\
-1.09 \\
-1.40 \\
-1.62 \\
-0.37 \\
-0.02 \\
-1.90^{*} \\
1.02 \\
\end{array}$ & $\begin{array}{l}\mathrm{p} \\
.89 \\
.28 \\
.16 \\
.11 \\
.71 \\
97 \\
.06 \\
.30\end{array}$ \\
\hline
\end{tabular}

In order to see if there were any significant difference between high and low attriters in terms of their MI profile scores, an Independent Sample Test was run for each of the forms of intelligence. As the table above shows, intrapersonal intelligence $(\mathrm{t}(52)=-1.90, \mathrm{p}=.06<.1)$ turned out to be significantly different for high and low attriters. However, the results for the rest of the forms of intelligence were not significant.

\section{Conclusions}

This study has showed that the spread of activation referred to by Damian et al. (2001) has survived through several years of disuse; indeed, large numbers of attrited words were reactivated at both levels through the initial activation by the researcher. Hence, exponents of teaching vocabulary in semantic sets should reconsider their view, given that the spread of activation, as shown in this study, is long-lasting and not limited to the learning period. Furthermore, in contrast to Atkins (2001), this study lends support for the part-set effect; the activation of an attrited word resulted in the activation of other attrited words, and this inconsistency with his study might be due to the inclusion of semantic sets in this study. Moreover, many studies in the literature have claimed that the process of relearning an attrited language proceeds more quickly than that of learning it for the first time. It could be hypothesized that the spread of activation, following initial activation, leads to the activation of other attrited words in that semantic set.

The results of this study show that in both lower-intermediate and beginner participants, there was no significant difference between the spread of activation at the recognition and production levels. It is possible that this inconsistency with Hansen's (2001) idea about the difference between activation at production and recognition levels could be ascribed to the limited number of participants, the absence of abstract words from the 133-word list, or the high frequency of the words chosen in this study; that is to say, possibly because the words are frequent, even a minimum of activation is sufficient for activation at the level of production as it is for the recognition level. The results of this study also show that in contrast to Cohen's (1986) idea about the potential of each exposure to increase learners' depth of knowledge about a word, a higher proficiency level, which is usually attained through more exposure, does not lead to a significantly different spread of activation at the production and recognition 
levels in lower-intermediate participants as compared to beginner participants. This inconsistency with Cohen's (1986) idea might be due to the inclusion of concrete and/or high frequency vocabulary words on the word list. In other words, a significant difference between the two groups could have been observed if the words were infrequent or abstract.

Generally speaking, the results of this study shed some light on the nature of the spread of activation among attrited semantically related words. Results show that the length of disuse appears to be unrelated to the spread of activation at both levels. The result is consistent with that of Meara (2004), who described simple computer simulation models of vocabulary attrition based on which he strongly suggested that the underlying structure of lexicon persists even when the words in a lexicon are deactivated.

In summary, the present study suggests that the spread of activation among words in attrited semantic sets is unrelated to the length of disuse and does not seem to be strengthened through further exposure.

This study has also shown that in the low-attriter group, there was a significant negative relationship between musical intelligence and the amount of attrition. Therefore, it could be suggested that improving musical intelligence and using musical-intelligence-based tasks, might be one of the factors that reduce the amount of attrition in this group. However, it should be pointed out that this should not be generalized to other contexts; it is only definitely true for this study. Also, musical intelligence should be considered as merely one of the many influencing variables; according to Oxford (1982), there are many variables that might influence the amount of attrition.

The results of this study also show that low attriters scored higher than high-attriters for all the forms of intelligences except for natural intelligence. Moreover, the scores for intrapersonal intelligence were significantly different between the two groups of attriters. Shearer (2006) remarked that in his study, intrapersonal intelligence can help learners to self-manage their anxiety when faced with unknowns. The same explanation can be used here for low attriters. It appears that the above-mentioned idea may be true about the low-attriters in this study. It should be noted, however, that this result should not be generalized to other situations because it is true only for this study, which is focusing on frequent concrete words with learners who have experienced a period of disuse of a particular length and who exhibit a particular proficiency level.

Oxford (1982) points out that there are various variables that might influence the amount of attrition, including problem-solving skill, general cognitive ability, verbal ability, demographic variables, etc. Furthermore, cognitive ability according to Johnson and Johnson (1999) consists of intelligence and aptitude. As one can see, there are many variables influencing the amount of attrition, and multiple intelligences are just a few of them, within which only intrapersonal form of intelligence was significantly different between the two groups of attriters in this study. Therefore, one can see that this form of intelligence identified here provides just a portion of the picture as a whole- besides which fact there is also a need for further research to replicate these findings.

In conclusion, this study lends support to the concept of the part-set effect and shows that there is no significant difference in the spread of activation in semantic sets between production and recognition levels in lower-intermediate and beginner participants. Furthermore, the spread of activation is not strengthened with more exposure to the language, and it is unrelated to the length of disuse. Additionally, it has been demonstrated that musical intelligence in low-attriters 
was negatively correlated with the amount of attrition in this study. And, as far as differences between high and low attriters are concerned, intrapersonal intelligence turns out to be significantly different between the two groups.

However, to conclusively support these pedagogical conclusions about multiple intelligences, further investigations must replicate them and also see if, and how far, the development and involvement of these forms of intelligence reduces the amount of attrition.

\section{Limitations}

It should be noted that the results of this study ought to be viewed cautiously because the number of participants is limited and the semantic sets studied here are limited to high frequency concrete words.

\section{ACKNOWLedgement}

I hereby would like to extend my appreciation to professors de Bot and Meara for their kind answers to my questions; I would also like to thank Dr. Shearer at the University of Kent for assessing the completed MI questionnaires. My greatest appreciation goes to my wife and my parents, who encouraged me to conduct this research.

\section{REFERENCES}

Atkins, P. W. B. (2001). "What happens when we relearn part of what we previously knew? Predictions and constraints for models of long-term memory". in Psychological Research, 65: 202-215.

Cohen, A. (1986). "Forgetting foreign language vocabulary", in B. Weltens, K. de Bot and T. van Els (eds.), Language attrition in progress. Dordrecht, the Netehrlands: Foris, 143-158.

Damian, M. F., Vigliocco, G. and Levelt, W. J. M. (2001). "Effects of semantic context in the naming of pictures and words". in Cognition, 81:77-86.

de Bot, K. and Stoessel, S. (2000). "In search of yesterday's words: Reactivating a long-forgotten language", in Applied Linguistics, 21/3:333-353.

de Bot, K., Martens, V. and Stoessel, S. (2004). "Finding residual lexical knowledge: The "Savings" approach to testing vocabulary", in International Journal of Bilingualisim, 8: 373-382.

de Groot, A. and Keijzer R. (2000). "What is hard to learn is easy to forget: The roles of word concreteness, cognate status, and word frequency in foreign language learning and forgetting", in Language Learning, 50/1: 1-56.

Finkbeiner, M. and Nicole, J. (2003). "Semantic category effects in second language word learning", in Applied Psycholinguistics, 24:369-383.

Hansen, L. (2001). "Language attrition: The fate of the start", in Annual Review of Applied Linguistics, 21: 60-73.

Hansen, L., Umeda, Y. and Mckinney, M. (2002). "Savings in the relearning of second language vocabulary: The effect of time and proficiency", in Language Learning, 52, 4: 653-678. 
Jaspert, K. and Kroon, S. (1989). "Social determinants of language loss". I.T.L, 83-84:75-98.

Johnson, K. and Johnson, H. (eds.)(1999). Encyclopedic dictionary of applied linguistics. USA: Blackwell Publishers Ltd.

Kopke, B. (2004). "Neurolinguistics aspects of attrition", in Journal of Neurolinguistcis,17:3-30.

Mahdavy, B. (2008). "The role of Multiple Intelligences (MI) in listening proficiency: A comparison of TOEFL and IELTS Listening Tests from an MI perspective", in Asian EFL Journal, 10,3, 5: 109-126.

Marefat, H. and Rouhshad, A. (2007). "Second language attrition: Are different nouns equally likely to be lost?", in Porta Linguarum, 8: 85-98.

Meara, P. (2004). "Modelling vocabulary loss" in Applied Linguistics, 25/2: 137-155.

Neely, J. H. (1991). "Semantic priming effects in visual word recognition: A selective review of current findings and theories", in D. Benser and G. Humphreys (eds.), Basic processes in reading: Visual word recognition. Hillsdale, NJ: Erlbaum, 264-336.

Oxford, R. (1982). "Research on language loss: A review with implications for foreign language teaching", in The Modern Language Journal, 66:160-169.

Poying, L. (n.d.). "Multiple intelligences theory and English language teaching". Available from: www. 52en.com, accessed 21 March, 2009.

Shearer, C. B. (1996). Multiple intelligences developments assessment scales (MIDAS). United States of America: Author.

Shearer, C. B. (2006). "Reading skill and the multiple intelligences: An investigation into the MI profiles of high school students with varying levels of reading Skill". Available from: www. Miresearch.org/files/Reading MI.doc accessed 3 November, 2009.

Tomiyama, M. (1999). "The first stage of second language attrition: A case study of a Japanese returnee", in L. Hansen (ed.). Second language attrition in Japanese contexts. New York: Oxford University Press, Inc,59-79.

Vago, R. M. (1991). "Paradigmatic regularity in first language attrition" in H. W. Seliger and R. M. Vago (eds.), First language attrition. Cambridge: Cambridge University Press, 241-252.

Weltens, B. and Grendel, M. (1993). "Attrition of vocabulary knowledge", in R. Schreuder and B. Weltens (eds.), The bilingual lexicon. Amsterdam: John Benjamin, 135-156.

Williams, H. (2006). "Maths in the grammar classroom", in ELT Journal, 60, 1: 23-33.

Yukawa, E. (2001). "Second language attrition in Japanese contexts", in Applied Linguistics, 21, 1:124-129. 